\title{
An Accurate-Simplified Haldane Gas Analyzer
}

\author{
By \\ Richard V. Ganslen \\ From the Department of Physiology, University of Arkansas \\ and \\ Leroy Sterling \\ From the Physical Fitness Research Laboratory, \\ University of Illinois \\ (Received for publication, November 14, 1957)
}

The apparatus depicted here is our vérsion of a simplified Haldane Respiratory Gas Analyzer which preserves the accuracy of the original machine, but is much less expensive, simpler to operate and easier to fabricate. The cost of constructing this particular machine did not exceed $\$ 35$, of which $\$ 20$ went to purchase the Haldane burette itself.

The most unique aspect of this machine is the complete elimination of the "thermobarometric compensator" from the circuit, a justification for which will appear in the body of the paper along with a detailed discussion of the analytical procedure. With the apparatus described herein we are able to complete a single analysis in 8 minutes. On good days, and all technicians have such days, we can successfully manage four duplicate determinations per hour.

Our laboratory files indicate replicate analyses of carbon dioxide within $.02-.03 \%$. Although the range for oxygen determinations is usually somewhat greater than Haldane claimed for his original machine $(.02 \%)$, our oxygen determinations seldom vary by as much as $.05 \%$ and are usually much closer than this. These figures compare quite favorably with the work of other laboratories.

\section{Construction}

The standard Haldane burette is usually delivered with a stopcock at the lower end and the tube in this region is usually quite constricted. After calibration, we remove the stopcock and restricted portion of the tube, which does not affect the calibration at all, in order to speed up the flushing action in the burette. The calibration technique suggested by Croton ${ }^{11}$ is an excellent method.

The apparatus as a whole is mounted on a piece of half-inch plywood about $75 \mathrm{~cm}$. in height with a baseboard about $25 \times 80$ centimeters which gives it stability. The center of the board is cut out (see dotted lines) to permit light 
from a 15-watt neon bulb to shine through the burette. To insulate the burette, a piece of opalescent blue or white glass is placed between the light and the burette water jacket. Behind stopcocks (A) and (B), holes of about one inch in diameter are bored to permit the apparatus to lie flat against the board. On the upper right-hand corner a "hook-eye" such as one uses to latch a door must be screwed to the board and a long piece of stout cord strung through it and down the back of the board. Behind the board the string is tied to a $50 \mathrm{ml}$. polyethylene bottle which acts as a counterbalance for the leveling bulb $(L)$. The bottle can be filled with some surplus mercury. The hook-eye and string should permit some drag on the lip of the board for smooth action during minor adjustments of the leveling bulb. The leveling bulb should be attached to the string with some type of a hook so that it can be easily detached during the time the burette gases are being flushed into the absorbing solutions.

There are many different methods of mounting the flushing arms (B-O) and (B-K), but the simplest method is to drill small holes directly behind the arms themselves and wrap soft aluminum or copper wire around the tubing, which is then twisted together behind the board. This simple set-up permits ready disassembly of the apparatus for cleaning.

The U-tubes $\mathrm{K}$ and $\mathrm{O}$, which hold the absorbing solutions in this set-up, are arranged so that they can be moved up and down a centimeter or so during the course of the analysis or clearing operation. The reason for this will be explained in detail later.

The clamps used to hold the flushing chambers were found in a hardware store and are often used to hold round handled household tools up against a wall. A rubber band twisted across the front assures us that the tube cannot slip out of its own accord. The weight of the absorbing solution itself should never move the containers.

The bore of the U-tubes should be about $30-35 \mathrm{~mm}$. and permit free entrance of the flushing tubes $\mathrm{K}$ and $\mathrm{O}$. If the tubes are too narrow a "capillarity" situation will be created which may expose the absorbing solution to air or permit oil to get in under the flushing chamber proper.

Stopcock $A$ is connected to the flushing arms with clear latex or plastic tubing for ease of disassembly. The sample tube $(S)$ is connected to the burette through stopcock $A$ with a long, snug piece of latex rubber. It should be necessary to moisten the end of the sample tube with saliva to insert it into its proper connection. Do not connect flushing chamber with stopcock B or, do not connect stopcock $B$ to A filling the flushing chambers!

After the absorbing solutions have been poured into their respective containers they should be covered with a layer of paraffin oil. With marks $(m-1)$ and (m-2) in place, the apparatus is ready for use.

\section{Preparing the Analyzer for Use (Clearing)}

At this time no sample tube is mounted and stopcock $\mathrm{A}$ should be open to room air. Lowering of the leveling bulb $L$ should now draw room air into the burette, where a sample of about $9 \mathrm{ml}$. should be taken. Proceed as follows : 


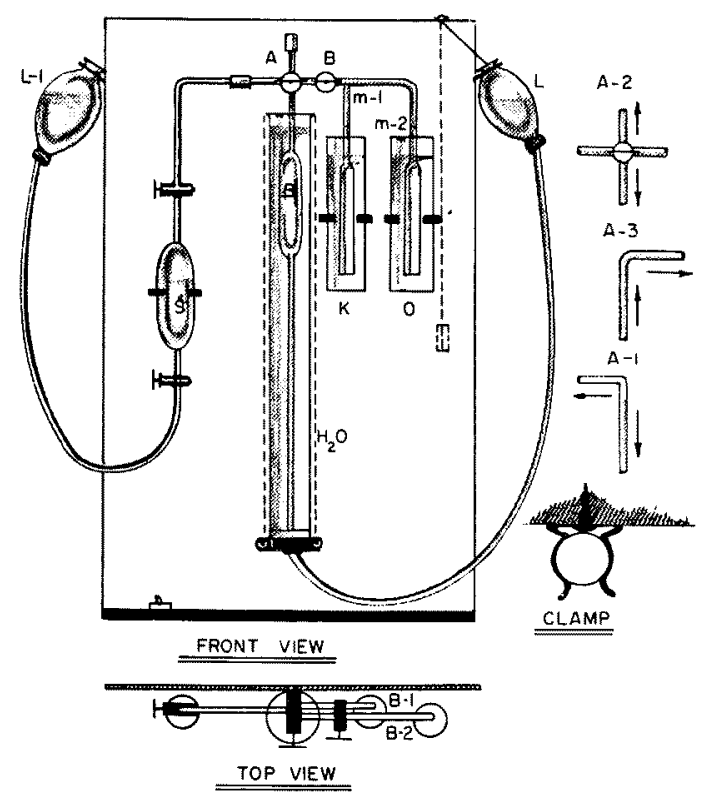

Fig. 1. Ganslen-Sterling modified Haldane analyser in diagram.

Turn stopcock A to position A-3 which closes the burette to outside air and connects the burette with stopcock $\mathrm{B}$. Open stopcock $\mathrm{B}$ to the $\mathrm{CO}_{2}$ absorbing solution in $\mathrm{K}$. Flushing 20 times into $\mathrm{K}$ should eliminate any $\mathrm{CO}_{2}$ in the machine. Return the fluid in $\mathrm{K}$ by leveling approximately to the mark $\mathrm{m}-1$ and rotate the stopcock $\mathrm{B}$ to position $\mathrm{B}-2$, which will now connect the burette with the oxygen absorber in $\mathrm{O}$. Flush 30 times into the oxygen absorber and level the solution to the mark m-2. Now, switch back to the $\mathrm{CO}_{2}$ absorber arm $\mathrm{K}$ by turning stopcock $\mathrm{B}$ to position B-l again. Flush here four or five times and return again to the oxygen-absorber side. The purpose of this return is to eliminate any oxygen from the arm between $B$ to $K$ which may have been trapped there during the first flushing operation. Now again flush 20 times into the oxygen absorber and level to the mark $m-2$. If on standing there is no creeping of the mercury in the burette (indicating additional oxygen absorption) the clearing operation has been completed. If there is a noticeable creeping of mercury in the burette between two successive readings, the machine is not clear and an additional 10 flushes into the oxygen absorber should be made.

\section{Balancing the Machine}

Assuming that the machine is now filled with nitrogen, we can level and balance the apparatus. Stopcock B should still be in position B-2. Bring the oxygen absorber carefully to the mark $\mathrm{m}-2$, where the fluid level should be steady. Now, turn the stopcock back to connect with the $\mathrm{KOH}$ carbon dioxide absorbing side. You may now notice a rise or fall in the level of the fluid around 
the mark $\mathrm{m}-1$ in the $\mathrm{CO}_{2}$ absorbing arm. This rise or fall is due to the presence of a pressure imbalance in the system. That is to say, there is a differential in pressure between the stopcock and $\mathrm{O}$ and the stopcock and $\mathrm{K}$. Such pressure imbalances often arise initially because the volume of absorbing solution in the chambers is not exactly the same, or the bore of the tubes on both sides may not be identical. Even the difference in SPG of the two solutions could be at fault.

Let us assume that upon turning stopcock $\mathrm{B}$ to $\mathrm{K}$ the fluid level fell below the mark m-1. Rather than try to add more solution on this side, which would correct the difficulty, slide the U-tube upward slightly until the fluid level is again at the mark m-1. To test the effectiveness of your correction, now rotate stopcock $B$ back and forth between chambers $I$ and $O$. If you have carried out the balancing procedure properly there should be no change in the fluid levels in either arm around their respective marks $m-1$ and $m-2$. You are now ready to make an analysis.

\section{Analytical Procedures}

The machine has now been cleared and switching stopcock B back and forth does not change the level of the fluids in the two absorbing chamber arms around their marks $\mathrm{m}-\mathrm{l}$ and $\mathrm{m}-2$. First turn stopcock $\mathrm{A}$ toward the sample tube $\mathrm{S}$. Insert the sample tube outlet connections into the rubber sleeve so that it is connected to stopcock A. Hang the leveling bulb for the sample tube. Open stopcock A to position A-1. Upon opening the upper and lower stopcocks of the sampling tube $(\mathrm{S})$, the respiratory sample will now be under positive pressure and free to enter the burette. Since there is some dead space between stopcocks $A$ and the sample tube proper, it is necessary to flush this gas out in order to obtain a representative gas sample. Proceed carefully as follows:

Unhook the leveling bulb L and grasp stopcock A in the left hand. Carefully lower the leveling bulb until the mercury in the burette begins to approach the $6 \mathrm{ml}$. mark, at the base of the broadened area of the burette. Do not lower the bulb rapidly or you may use up too much of your sample in flushing the burette and have none left for analysis. Now, elevate the leveling bulb $\mathbf{L}$ and, as soon as the mercury in the burette bulb begins to climb, open stopcock $\mathrm{A}$ to room air, position A-2. This procedure will drive out 5 or $6 \mathrm{ml}$. of gas flushed from the arm between the stopcock and the sample tube proper. On elevation of the leveling bulb, the mercury will surge rapidly upward; therefore, as soon as it begins to approach the upper neck of the burette, under stopcock A, turn stopcock A back to the sample and lower the leveling bulb again. Stopcock $A$ must never be opened to room air unless an over-pressure of gas exists in the burette proper, i.e., while the mercury column in rising; otherwise, room air will enter the burette and contaminate the sample. Repeat this flushing procedure four or five times, depending on how much sample you have to work with. On the last flush, attach the leveling bulb to its counterbalance. Stopcock A should still be in position A-1. The next maneuver is critical!

Remove the leveling bulb belonging to the sample bulb from its hook and carefully level the mercury in this bulb with that showing in the sample tube 
itself at this moment. To guide this tube it is sometimes desirable to place one finger along the side of the board for friction. Level as accurately as possible, since this step will determine whether you are creating any overpressure or underpressure of the gas in the burette, which gas you are about to analyze. If there is any reason to suspect that you can not level these two tubes perfectly, (and no one can!) apply a slight over-pressure by elevating the mercury in the leveling bulb L-1 a fraction of a cent. Check the mercury level at the base of the burette and, if it has climbed the burette, lower the leveling bulb $\mathrm{L}$ to make sure you get at least a 9-ml. sample. Turn off the upper stopcock of the sample tube and re-hang this leveling bulb, L-1. There is no need to touch stopcock A at this time.

Since we balanced the machine earlier in clearing we can proceed with the analysis. Turn stopcock A to position A-3, which again connects you with the $\mathrm{KOH}$ absorber. You will probably note a slight rise or fall of the $\mathrm{KOH}$ solution around the mark $\mathrm{m}-\mathrm{l}$ because your sample tube leveling procedure was not perfect. It seldom is. Now, without undue haste, but smoothly, lower or elevate the leveling bulb (L) to bring the solution to the mark m-1 and read your initial gas volume. Flush 20 times, level, and read again as you did in clearing the machine. The carbon dioxide has now been absorbed. Upon turning to the oxygen absorber there should not be any change in the level of the solution around the mark m-2 unless you balanced the machine improperly after clearing it. If a fractional movement of the fluid is noted, don't get excited. Level immediately and read the gas volume. This minor re-adjustment on the oxygen absorbing side, if accomplished rapidly, will not result in any significant loss of oxygen from the sample to the absorber, but any delay here might be disastrous to your results. Flush as described previously in clearing the machine, 50 to 60 total flushes on the oxygen-absorbing side, until no creeping of the mercury in the burette takes place when the leveling bulb has been re-hung. Read your final gas volume. With the completion of this analysis (which takes about 8 minutes for an experienced operator), you will be ready for the next sample without the necessity of the clearing operation. Always check the gas pressure balance in the machine before taking in a new sample and re-balance if necessary. When allowing the machine to stand, leave the burette connected with the oxygen absorber as a matter of general practice, since carbon dioxide is easy to clear out of a machine.

\section{Discussion}

The thermobarometric compensator was included in the original Haldane analyzer described by Consolazio, Johnson and Marek ${ }^{2)}$ to take care of the differential pressure changes in the apparatus arising from or accompanying the exothermic reactions which take place during the absorption of carbon dioxide and oxygen. In order to evaluate this temperature factor the water jacket bathing the burette was fitted with an extremely sensitive Leeds Northrup potentiometer sensitive to $.01^{\circ}$ 
temperature changes. The fluctuations resulted from the analysis itself are tabulated below.

$\begin{array}{lccc} & \text { Readings (mv) } & \text { Time } & \text { Temperature } \\ \text { Start } \mathrm{KOH} \text { flush } & .964 & 9: 21 & 24.44 \\ \text { Finish " } & .964 & 9: 23 & \\ \text { Start } \mathrm{O}_{2} \text { flush } & .965 & 9: 23 & 24.44 \\ \text { Reflush } \mathrm{KOH} & .966 & 9: 24 & \\ & .966 & & \\ \text { Return } \mathrm{O}_{2} \text { flush } & .966 & & \\ & .967 & 9: 26 & 24.50 \\ \text { Continue } \mathrm{O}_{2} \text { flush } & .968 & & \\ & .969 & 9: 27 & \\ \text { Analysis complete } & .969 & & 24.50 \\ & .969 & & \\ & .969 & 9: 30 & .06^{\circ} \text { Centigrade }\end{array}$

It should be pointed out that this net difference in temperature fluctuation resulted after 9 minutes of continuous flushing. The temperature difference is insignificant.

Asmussen $^{3)}$ found that the use of the thermobarometer in the Scholander apparatus is superfluous and we are convinced that the same situation is true with this apparatus. The principal causes of the gas pressure imbalances in this work do not result from the exothermic reactions during the analysis or variations in the atmospheric pressure, but are the consequence of careless balancing the machine at the completion of the clearing operation or improper leveling of the sample tube leveling bulb L-1 mercury when the sample is brought into the burette. Routine errors involved in Haldane Gas analysis work are admirably evaluated in a fine paper by Renburn and McK. Ellison ${ }^{4)}$ which should be read by all workers in this field.

As in all gas analysis work, a routine analytical procedure must be perfected. There are probably more errors in taking gas samples from bags than there are in actually making the analysis. Any one intending to do gas analysis work must have some elementary knowledge of the principles of gas pressures. A hasty movement in gas analysis work can easily flood the burette with absorbing solution and require an hour of cleaning before one can get back into operation. This machine is unusually easy to clean.

It is preferable to make the absorber arms short to reduce the dead space in the machine to a minimum, capillary tubing is recommended throughout. The horizontal tubes leading to $\mathrm{K}$ and $\mathrm{O}$ can be as little as 6 or $7 \mathrm{~cm}$. long, while the vertical leading to the inverted funnel might be about another 8 to $10 \mathrm{~cm}$. By making these arms short, the efficiency 
of the flushing operation is improved, but there is also greater danger of flooding the burette with a careless movement. It is desirable to keep the vertical chambers $\mathrm{K}$ and $\mathrm{O}$ as closely parallel to the burette proper as possible. This will reduce eye movements to a minimum.

I prefer the use of sodium hydrosulfite $(8 \mathrm{~g}$.) mixed with sodium anthraquinone beta sulfonate ( $1.5 \mathrm{~g}$.) and a crystal of ferric chloride for absorbing oxygen. The solution is mixed with $50 \mathrm{ml}$. of warm $\left(50^{\circ} \mathrm{C}\right) 14 \%$ $\mathrm{KOH}$ solution and cooled under running water before being added to the machine. When this mixture is absorbing oxygen, a distinct white crust forms on its surface and may even coat the tube of the absorber arm, but as the oxygen absorption is completed the crust completely disappears. This crust formation is a rough check on the presence of oxygen in the burette during the flushing operation.

In order to reduce the arm stroke during flushing to a bare minimum, keep the rubber hose connecting the leveling bulb (L) as short as possible. The total amount of mercury contained here is thus reduced and faster flushing is possible.

An operator must always take care to see that he does not take in too much sample from the sample tube. Should this sample be too large, more than $9 \mathrm{ml}$., and the leveling action of the sample bulb be too inaccurate, it will be necessary to lower the leveling bulb (L) again to bring the $\mathrm{KOH}$ solution to the mark $\mathrm{m}-\mathrm{l}$ for the initial gas volume reading and this may drop the mercury out of the calibrated area of the burette. Technically, the larger sample may be better, but practically it may prove impossible to analyze the larger sample.

\section{Conclusion}

This apparatus design completely eliminates the thermobarometric compensator. By making the U-tubes holding the absorbing solutions movable, overpressures and underpressures noted in clearing the machine can be compensated for in this apparatus. The principal cause of the initial internal differential pressures in the machine is the inability of an operator to level the mercury of the sampling bulb, and the leading bulb L-1, in perfectly. This situation sets up a differential pressure situation in the burette which evidences itself upon switching to the carbon dioxide absorbing solution and must be compensated for immediately.

For a detailed discussion of errors in respiratory gas analysis worker the readers are referred to the work of Renburn and McK. Ellison. ${ }^{4)}$

\section{References}

1) Croton, L. M., Science Technologist Assoc. Bull., 1951, 2, 2. 
2) Consolazio, C. F., Johnson R. E. \& Marek. E., Metabolic methods. C. V. Mosby, St. Louis, 1951, 313.

3) Asmussen, E., Personal communication 1949.

4) Renburn, E. T. \& Ellison. J. McK., J. Hyg., 1950, 48, 239. 